\title{
Initial Spiritual Screening and Assessment: Five Things to Remember
}

\author{
Elizabeth Johnston Taylor, Ph.D., R.N., FAAN \\ School of Nursing, Loma Linda University, Loma Linda, CA, USA
}

To deliver holistic and person-centered palliative care (PC), the spiritual dimension must also be assessed. However, many nurses do not screen for or assess patient spirituality. This article presents five things that PC nurses can consider in order to improve their spiritual screening and assessment practices. These points are as follows: (1) Understand that spirituality is manifest in a myriad of ways and is not the same thing as religiosity. (2) Screen for spiritual distress, and then later conduct a spiritual history or assessment. (3) Remember that spirituality is not just something to assess upon admission. (4) Know that there are many ways to assess spirituality (it is not merely how a patient verbally responds to a question about spirituality or religiosity). (5) Remember that assessment can also be therapeutic.

Key Words: Spirituality, Palliative care, Hospices, Nurses, Religion
Received October 28, 2019 Accepted October 28, 2019

Correspondence to
Elizabeth Johnston Taylor
School of Nursing, Loma Linda
University, 1555 Loma Linda Vista
Ave., Pasadena, CA 91103, USA
Tel: +1-909-747-8836
E-mail: ejtaylor@llu.edu

\section{INTRODUCTION}

The World Health Organization (WHO) and other leading organizations shaping palliative care (PC) define it as holistic; that is, it involves caring for the entire person, including the spiritual dimension (1,2). Given this definition, and the reality that persons living with a life-limiting or threatening illness often experience spiritual challenges and religious struggles (35), it is imperative that nurses know how to properly screen for spiritual distress and assess spiritual resources and needs. Indeed, every nurse understands that prior to delivering holistic and person-centered nursing care, the patient must be assessed. How else will nurses know what the patient needs and prefers? This is true not only for physical and psychological health problems but also for spiritual needs (6).

However, there is evidence that many nurses do not screen for or assess patient spirituality (7). Reasons for this finding may include a perceived lack of time; privacy; ability, skill, or knowledge; and a lack of understanding about what spiritual care is and the appropriateness of including spiritual care within nursing care (8-10). Many nurses never receive training on how to conduct spiritual screenings or assessments. Without training, nurses who are religious may rely on their own personal religiosity for guidance on how to assess and address patient spiritual needs. Nurses who are not aware of personal spirituality may wonder how to discuss it with patients. Thus, this article provides an introduction to this topic. By remembering these five points, PC nurses can improve their spiritual screening and assessment practices.

\section{UNDERSTAND THAT SPIRITUALITY IS MANIFESTED IN A MYRIAD OF WAYS; IT IS NOT THE SAME AS RELIGIOSITY}

A definition for spirituality written by a consensus of $\mathrm{PC}$ ex- 
perts from around the world helps us understand how spirituality and religiosity are similar but different (11). This definition states that:

Spirituality is a dynamic and intrinsic aspect of humanity through which persons seek ultimate meaning, purpose, and transcendence, and experience relationship to self, family, others, community, society, nature, and the significant or sacred. Spirituality is expressed through beliefs, values, traditions, and practices.

A patient's temple visits or church attendance, reading of religious texts, or private worship may be solely religiosity. Spirituality, however, may be manifested when a patient wants to spend time in nature, read inspirational poetry, create art, help a stranger, leave a legacy, or savor a meaningful memory. Thus, how persons express, nurture, and practice their spirituality varies widely.

Spirituality is manifested not only by practices and rituals but also in how people think and talk. For PC patients near the end of life, expressions of spirituality may be found in wondering what the meaning of their life as a dependent invalid is, or existential questions about why suffering and dying exist, or doubts about whether there is a loving or powerful divinity, or wishes to be reconciled with estranged friends or family, or ruminations about the life lived.

Thus, spiritual screening or assessment cannot be limited to asking, "what is your religion?". Instead, questions about what makes life purposeful or what gives inner strength and comfort will provide a better understanding of what deeply motivates the patient (12).

\section{SCREEN FOR SPIRITUAL DISTRESS, AND THEN LATER CONDUCT A SPIRITUAL HISTORY OR ASSESSMENT}

A decade ago, a large group of US American PC and spiritual care experts convened to identify guidelines for spiritual assessment and care (13). They concluded that all PC patients ought to be screened for spiritual distress upon admission. If distress is imminent, then referral to a spiritual care expert (e.g., chaplain, counselor with appropriate expertize) can be made immediately. Within a reasonable time after admission, a more detailed spiritual history or assessment should be completed and documented. They proposed that the history be completed by the primary care clinician (e.g., hospice physician or primary nurse), whereas the detailed assessment could be performed by the spiritual care expert on an "as-needed" basis.

Researchers have tested which spiritual screening questions are most sensitive for detecting spiritual distress (14). They observed that the following questions performed best in an American sample of cancer survivors:

- Do you struggle with the loss of meaning and joy in your life?

- Do you currently have what you would describe as religious or spiritual struggles?

Other screening questions could include as follows: Are you at peace? Does your $\mathrm{R} / \mathrm{S}$ provide you with all the strength and comfort that you need from it right now? Or, do you have any spiritual/religious concerns? (14) Some clinicians ask the question "How much pain do you have here [pointing to the heart]?”.

A spiritual history or more in-depth assessment is intended to determine how best to provide spiritual care. It seeks to understand in a cursory way the patient's spiritual beliefs and practices that would impact health and what spiritual support is wanted from the healthcare team. Examples of questions that would elicit this information include the following:

- What faith, religion, or spiritual perspectives influence how you care for your body?

- What religious or spiritual ritual or practices are important to you?

- How can our healthcare team show you that we support your spiritual well-being?

The questions must be culturally relevant, sensitive, and comfortable for nurses and patients alike. Thus, they may be pre-determined by the healthcare institution and incorporated into a standard assessment protocol. 


\section{KNOW THAT SPIRITUALITY IS NOT JUST SOMETHING TO ASSESS UPON ADMISSION; THEREFORE, CONTINUALLY ASSESS SPIRITUALITY}

One's spirituality is dynamic; it does not remain the same. The 2009 consensus panel recommended that patient spirituality be re-assessed whenever a change in the patient's condition occurs (13). An observant nurse, however, can always keep a "radar" on. Indeed, it is not unusual for patients to discuss spiritual pain during a conversation about physical pain or overtly describe it during a bed bath or backrub. Patients will also reveal much about their spirituality through the environment they create (e.g., shades drawn, few visitors, religious symbols at the bedside). Similarly, the stories patients tell or the emotions that reflect the spirit are also expressions of spirituality.

\section{APPRECIATE THAT THERE ARE MANY WAYS TO ASSESS SPIRITUALITY; IT IS NOT MERELY HOW A PATIENT VERBALLY RESPONDS TO A QUESTION ABOUT SPIRITUALITY OR RELIGIOSITY}

As implied earlier, nurses can sense much about a patient's spirits from their environment (e.g., religious jewelry or objects) and their non-verbal communication (e.g., tone of voice, facial expressions, body language). Even when considering what patients say, there is much about spirituality that is conveyed in "casual" comments (e.g., "Oh my God!", "It must have happened for a reason," or "Shit happens").

Much is also conveyed in the narratives a patient tells. These can be prompted by questions like those used during Dignity Therapy, a tested life review therapeutic widely found to be effective in improving quality of life and spiritual well-being for persons at the end of life $(15,16)$. Such questions include the following: "Tell me a little about your life history, particularly the parts you either remember most or think are most important? When did you feel most alive? Are there specific things that you would want your family to know about you? $\cdots$ ? What are the most important roles you have played in life $\cdots$ ? What are your most important accomplishments $\cdots$ ? Are there particular things that you feel still need to be said $\cdots$ ? What are your hopes and dreams for your loved ones? What have you learned about life that you would want to pass along $\cdots$ ? are there other things that you would like included?".

To provide empathic, healing responses to a patient's responses, nurses must listen and respond to the "cutting edge" theme of the story, the emotion in the story, and where the energy is placed (17). For example, nurse responses such as "I noticed your eyes teared up when you talked about your children" or "It seems like you've experienced a lot of [betrayal, gratitude, or whatever spiritual theme is observed] during your life" can help a patient gain insight into his or her life story (17).

\section{REMEMBER THAT ASSESSMENT CAN ALSO BE THERAPEUTIC}

Although assessment is considered the initial step of the nursing process, it doubles as an intervention in the context of spiritual care. To inquire about and deeply listen to a patient's spirituality is to convey care, provide witness to spiritual suffering or joy, and allow expression of spiritual distress and/or well-being. Such expressions can provide insight, maturation, or healing.

A survey of New Zealand hospice patients revealed that although some patients may not be very comfortable with a nurse asking a spiritual question, others (particularly religious patients) are. The survey did note that questions allowing a patient to recognize spiritual resources and strengths are particularly welcomed. Examples are the following: Who or what supports you when you are ill? When life is hard, how have you kept going? Is there anyone or anything that is helpful to you now (18)? These findings suggest that such positively framed questions may offer healing in that they allow the patient to appreciate resources and feel gratitude - this is therapeutic!

\section{CONCLUSION}

Although PC and hospice nurses typically provide more spiritual care than nurses in other subspecialties $(19,20)$, com- 
pleting spiritual screenings and more in-depth assessments remains difficult. Spiritual screening and assessment, however, are pivotal to person-centered holistic care. The five points provided here can make the process less anxiety producing and more integral to interactions with patients.

\section{REFERENCES}

1. National Consensus Project for Quality Palliative Care. Clinical practice guidelines for quality palliative care [Internet]. Pittsburgh: National Consensus Project for Quality Palliative Care; 2018 [cited 2019 Oct 24]. Available from: https://www.nationalcoalitionhpc.org/ncp/.

2. World Health Organization. WHO Definition of palliative care [Internet]. Geneva: World Health Organization; 2019 [cited 2019 Oct 24]. Available from: https://www.who.int/cancer/palliative/definition/en/.

3. Delgado-Guay MO, Chisholm G, Williams J, Frisbee-Hume S, Ferguson AO, Bruera E. Frequency, intensity, and correlates of spiritual pain in advanced cancer patients assessed in a supportive/palliative care clinic. Palliat Support Care 2016:14;341-8.

4. Gillilan R, Qawi S, Weymiller AJ, Puchalski C. Spiritual distress and spiritual care in advanced heart failure. Heart Fail Rev 2017;22:581-91.

5. Hui D, de la Cruz M, Thorney S, Parsons HA, Delgado-Guay M, Bruera E. The frequency and correlates of spiritual distress among patients with advanced cancer admitted to an acute palliative care unit. Am J Hosp Palliat Care 2011;28:264-70.

6. Taylor, EJ. Chapter 41. Spirituality. In: Berman A, Snyder S, Frandsen G, eds. Kozier \& Erb's fundamentals of nursing : concepts, process, and practice. 11th ed. Hoboken, New Jersey:Pearson;2021.

7. Taylor EJ, Mamier I, Ricci-Allegra P, Foith J. Self-reported frequency of nurse-provided spiritual care. Appl Nurs Res 2017;35:30-5.

8. Gallison BS, Xu Y, Jurgens CY, Boyle SM. Acute care nurses' spiritual care practices. J Holist Nurs 2013;31:95-103.

9. Keall R, Clayton JM, Butow P. How do Australian palliative care nurses address existential and spiritual concerns? Facilitators, barriers and strategies. J Clin Nurs 2014;23:3197-205.

10. Selby D, Seccaraccia D, Huth J, Kurrpa K, Fitch M. A qualitative analysis of a healthcare professional's understanding and approach to management of spiritual distress in an acute care setting. J Palliat Med 2016;19:1197-204.

11. Puchalski CM, Vitillo R, Hull SK, Reller N. Improving the spiritual dimension of whole person care: reaching national and international consensus. J Palliat Med 2014;17:642-56.

12. Taylor EJ. Chapter 34. Spiritual screening, history, and assessment. In: Ferrell BR, Paice JA, eds. Oxford textbook of palliative nursing. 5th ed. New York:Oxford University Press, cop.2019.

13. Puchalski C, Ferrell B, Virani R, Otis-Green S, Baird P, Bull J, et al. Improving the quality of spiritual care as a dimension of palliative care: the report of the consensus conference. J Palliat Med 2009;12:885-904.

14. King SD, Fitchett G, Murphy PE, Pargament KI, Harrison DA, Loggers ET. Determining best methods to screen for religious/spiritual distress. Support Care Cancer 2017;25:471-9.

15. Fitchett G, Emanuel L, Handzo G, Boyken L, Wilkie DJ. Care of the human spirit and the role of dignity therapy: a systematic review of dignity therapy research. BMC Palliat Care 2015;14:8.

16. Wang CW, Chow AY, Chan CL. The effects of life review interventions on spiritual well-being, psychological distress, and quality of life in patients with terminal or advanced cancer: a systematic review and meta-analysis of randomized controlled trials. Palliat Med 2017;31:88394.

17. Taylor EJ. What do I say? Talking with patients about spirituality. Philadelphia:Templeton Foundation Press;c2007.

18. Taylor EJ, Brander P. Hospice patient and family cancer perspectives on nurse spiritual assessment. J Hosp Palliat Nurs 2013;15:347-54.

19. Ronaldson S, Hayes L, Aggar C, Green J, Carey M. Spirituality and spiritual caring: nurses' perspectives and practice in palliative and acute care environments. J Clin Nurs 2012;21:2126-35.

20. Taylor EJ, Highfield MF, Amenta M. Predictors of oncology and hospice nurses spiritual care perspectives and practices. Appl Nurs Res 1999;12:30-7. 